\title{
A METHOD FOR THE EXTRACTION OF LONG-TERM DEFORMATION CHARACTERISTICS OF LONG-SPAN HIGH-SPEED RAILWAY BRIDGES USING HIGH-RESOLUTION SAR IMAGES
}

\author{
H. G. Jia ${ }^{\text {a, b, c, d*, L.Y. Liu }}{ }^{\text {a }}$ \\ ${ }^{a}$ Faculty of Geosciences and Environmental Engineering, Southwest Jiaotong University, Chengdu, Sichuan, China \\ ${ }^{\mathrm{b}}$ State Key Laboratory of Geodesy and Earth's Dynamics, Wuhan, Hubei, China \\ ${ }^{c}$ Collaborative Innovation Center for Rail Transport Safety, Ministry of Education of the People's Republic of China, Southwest \\ Jiaotong University, Chengdu, Sichuan, China \\ ${ }^{\mathrm{d}}$ State-Province Joint Engineering Laboratory of Spatial Information Technology for High-Speed Railway Safety, Southwest \\ Jiaotong University, Chengdu, Sichuan, China
}

Commission VII, WG VII/2

KEY WORDS: InSAR, High Resolution, Deformation Characteristic, Long-term, Long-span Bridge

\begin{abstract}
:
Natural causes and high-speed train load will result in the structural deformation of long-span bridges, which greatly influence the safety operation of high-speed railway. Hence it is necessary to conduct the deformation monitoring and regular status assessment for long-span bridges. However for some traditional surveying technique, e.g. control-point-based surveying techniques, a lot of human and material resources are needed to perform the long-term monitoring for the whole bridge. In this study we detected the long-term bridge deformation time-series by persistent scatterer interferometric synthetic aperture radar (PSInSAR) technique using the high-resolution SAR images and external digital elevation model. A test area in Nanjing city in China is chosen and TerraSAR-X images and Tandem- $\mathrm{X}$ for this area have been used. There is the Dashengguan bridge in high speed railway in this area as study object to evaluate this method. Experiment results indicate that the proposed method can effectively extract the long-term deformation of long-span high-speed railway bridge with higher accuracy.
\end{abstract}

\section{INTRODUCTION}

Long-span bridges have complicated structure so that the safe operation of the bridges is sensitive to small deformations. Hence the deformation monitoring of long-span bridges needs high accuracy. Typical methods for the deformation monitoring are traditional engineering surveying techniques, methods using physical sensors and GPS surveying techniques. By these techniques, the absolute deformation information in local parts of bridges can be obtained. However, these techniques need amount of manpower and material resources, and are performed by some control points so that it is difficult to achieve the deformation information for the whole bridge. Recently, Interferometric Synthetic Aperture (InSAR) technique has been often applied (Ferretti et al. 2001, Berardino et al. 2002, Lanari et al. 2004, Hooper et al. 2007, Liu et al. 2009, Masahiro et al. 2010, Zhang et al. 2011, Ferretti et al. 2011, Wang et al. 2012) to solving these issues, because it can detect the deformation information for the whole target areas, and has high measurement accuracy and automatic degree, and few

* Corresponding author 
manpower, and so on. Currently, some SAR sensors with high spatial resolutions has been used, e.g. TerraSAR-X, COSMO-SkyMed, Sentinel-1 A and B, which can detect the deformation for very small object, e.g. a building. WorldDEM generated by TanDEM-X has the $10 \mathrm{~m}$ absolute vertical accuracy and $2 \mathrm{~m}$ relative vertical accuracy. This article aims to detect the deformation in long time series for the Dashengguan bridge in Nanjing by the integration of TanDEM and TerraSAR-X images.

\section{DEFORMATION MONITORING WITH PSINSAR}

\subsection{Study Area and Data Source}

Nanjing, the capital city of Jiangsu province, is in east China. The Dashengguan Bridge (See Figure 1) is located in Nanjing Jianye District and in this bridge, there are six railway lines, i.e. Peking to Shanghai, Shanghai to Chengdu, and Nanjing underground. This length of this bridge is $9.273 \mathrm{~km}$ and the load of this bridge is the highest in the world. Due to the great length, high load, high running speed, and complex structure, it is necessary to conduct a deformation monitoring in long time series for the safe operation of this bridge.

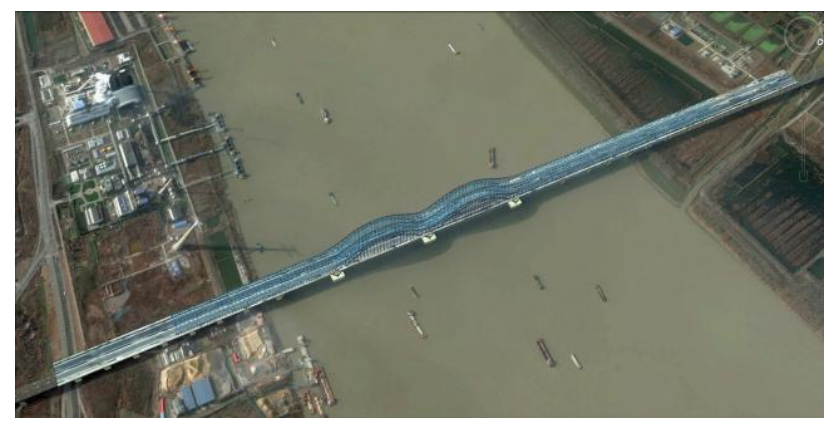

Figure 1. Dashengguan Bridge in Nanjing

In this study, 14 TerraSAR images acquired during descending pass between 31 May 2013 and 2 January 2016 were utilized. The time series of deformation at 7 PSs are derived (See Table $1)$.

\begin{tabular}{|c|c|c|c|}
\hline No. & Acquisition Time & No. & Acquisition Time \\
\hline 1 & 20130531 & 8 & 20141019 \\
\hline 2 & 20130714 & 9 & 20141202 \\
\hline 3 & 20130918 & 10 & 20150206 \\
\hline 4 & 20131123 & 11 & 20150527 \\
\hline 5 & 20140128 & 12 & 20150801 \\
\hline 6 & 20140518 & 13 & 20151028 \\
\hline 7 & 20140814 & 14 & 20160102 \\
\hline
\end{tabular}

Table 1. Acquisition Time of 14 TSX images

\subsection{Experimental results and discussion}

\section{A. Distribution of TCPs Identified for the Study Area}

In this study, 21 interferometric pairs formed by 14 TSX images are used to detect persistent scatterers (PSs). According to the correlation coefficients of all pixels on images, a threshold is given. If the correlation coefficient of a pixel is more than the threshold, it is selected as a PS point. By this method, 238552 PSs are selected from the study area and mainly the fence, hard shoulder and street lamp on the bridges.

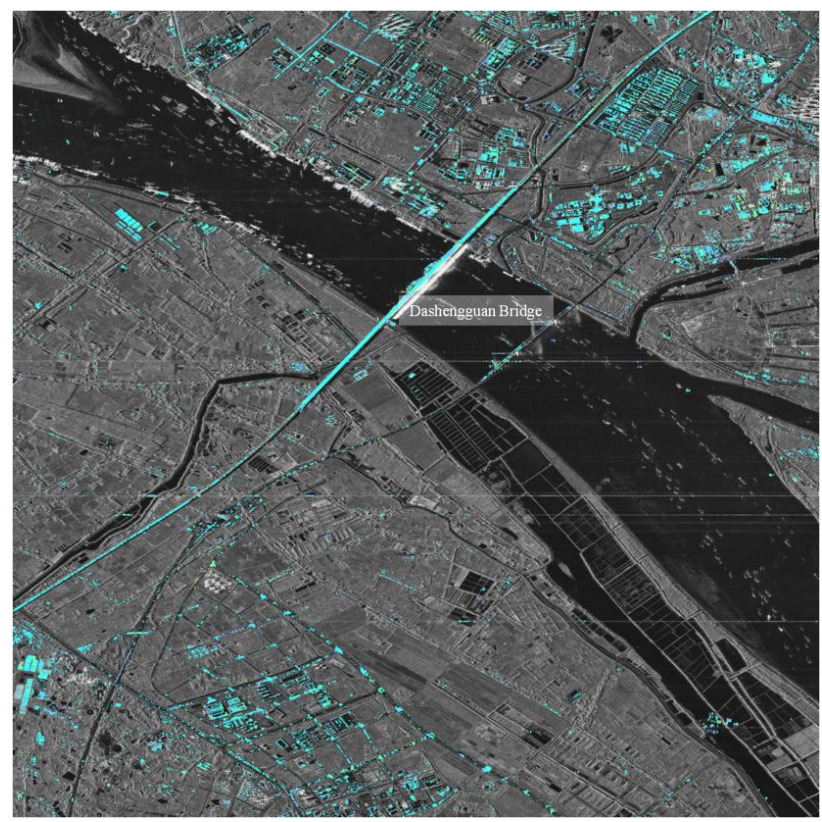

Figure 2. PS point distribution in study area.

\section{B. Subsidence Signature Derived from PS Solution}

The resultant subsidence rates at all the valid PSs are shown in Figure 3. The subsidence rates within the entire study area range between -40 and $30 \mathrm{~mm} / \mathrm{yr}$. In order to further analyze the finer deformation, six PS points are selected to achieve the time series of the deformation (See Figure 4). 


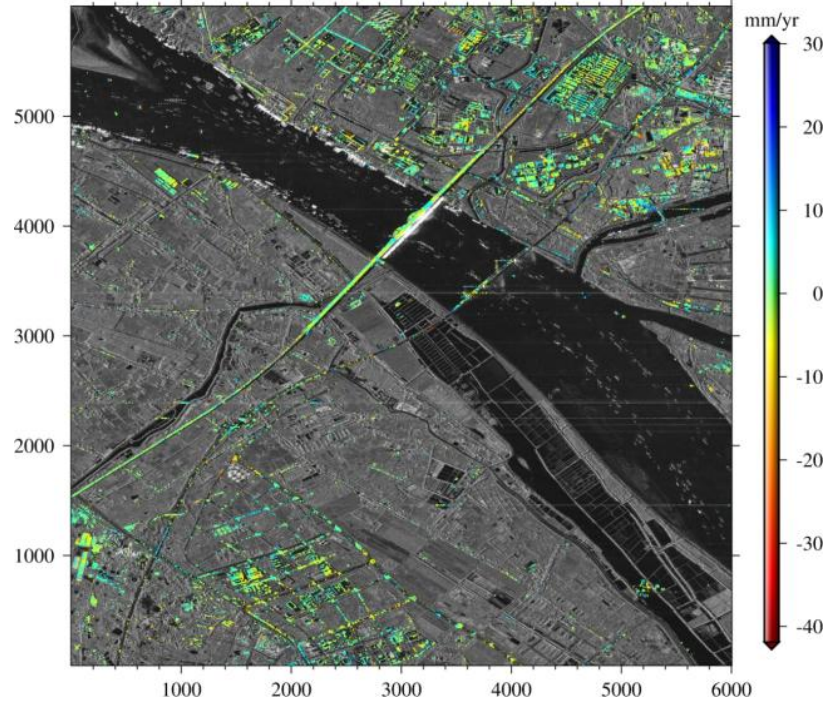

Figure 3. Deformation rates of the study area

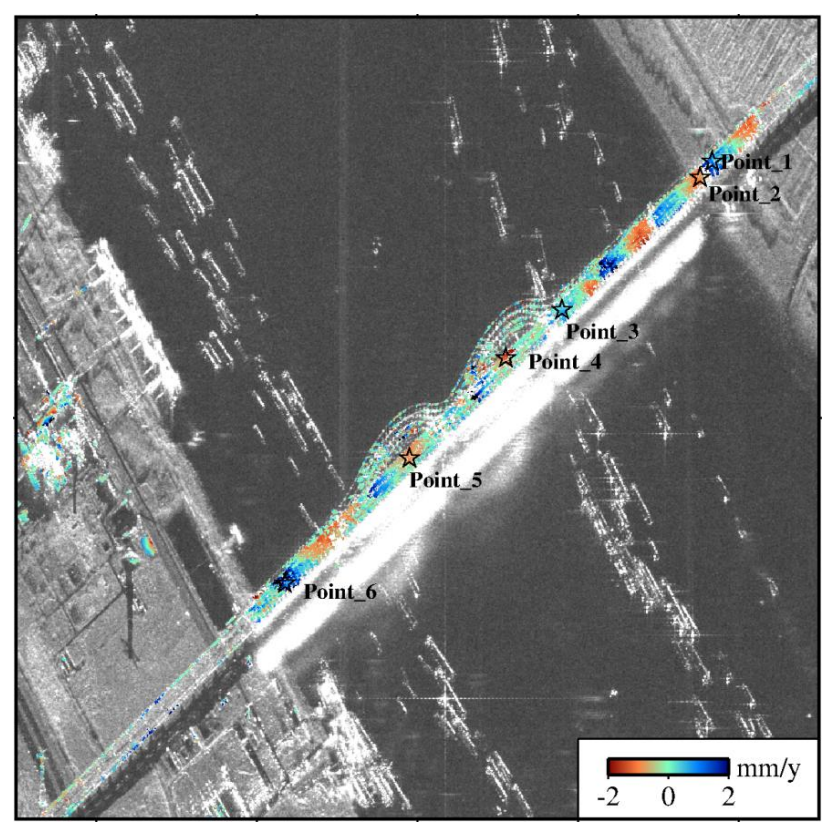

Figure 4. Deformation rates of bridge

As illustrated in Figure 4, the deformation rates change from $-2 \mathrm{~mm}$ to $2 \mathrm{~mm}$. The deformation rates of six PS points are shown in Figure 5. From the Figure 5, it is noted that the deformation periodically changes for different seasons. The reason may be the temperature influence in different seasons.

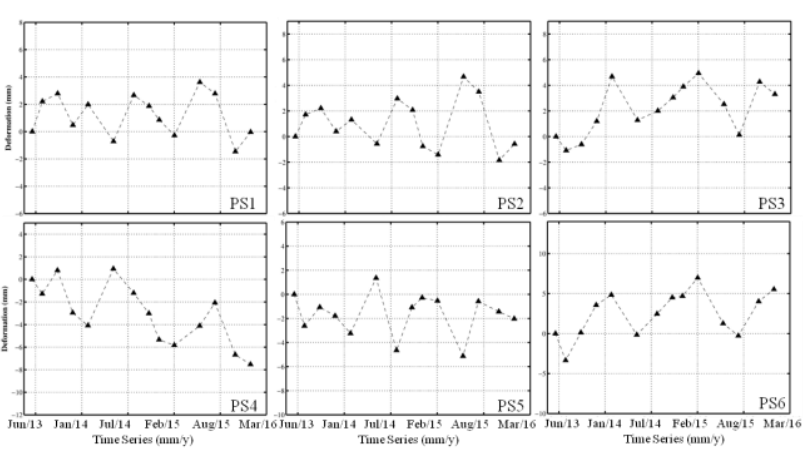

Figure 5. Deformation time series of 6 PSs

\section{CONCLUSION}

This article used PSI technique to detect the deformation information from 31 May 2013 to 2 January 2016 for Dashengguan Bridge in Nanjing. During the period of time, the deformation of the bridge is from $-2 \mathrm{~mm}$ to $2 \mathrm{~mm}$ and has a significant seasonal change, which may arise from the temperature factor. In future work, more TSX images are used to improve the reliability and accuracy of the finer deformation monitoring. In addition, the measurement data collected from leveling and GPS surveying will be used to evaluate the deformation results.

\section{ACKNOWLEDGEMENTS}

This project is supported by State Key Laboratory of Geodesy and Earth's Dynamics (SKLGED2015-5-1-E), the Fundamental Research Funds for the Central Universities (2682015CX015), the National Natural Science Foundation of China (41474003), Program for Changjiang Scholars and Innovative Research Team in University (IRT13092).

\section{REFERENCES}

Berardino, P., Fornaro, G., Lanari, R., Sansosti, E., 2002. A new algorithm for surface deformation monitoring based on small baseline differential SAR interferograms. IEEE Transactions on Geoscience and Remote Sensing, Vol.40, No. 1, pp.2375-2383.

Ferretti, A., Prati, C., Rocca, F., 2001. Permanent scatterers in SAR interferometry. IEEE Transactions on Geoscience and Remote Sensing, Vol.39, No.1, pp.8-20. 
Ferretti, A., Fumagalli, A., Novali, F., Prati, C., Rocca, F., Rucci, A., 2011. A new algorithm for processing interferometric data-stacks: SqueeSAR. IEEE Transactions on Geoscience and Remote Sensing, Vol.49, No.9, pp.3460-3470.

Hooper, A., Segall, P., Zebker, H., 2007. Persistent scatterer interferometric synthetic aperture radar for crustal deformation analysis, with application to Volca'n Alcedo, Gala'pagos. Journal of Geophysical Research, Vol.112, B07407.

Lanari, R., Mora, O., Manunta, M., Mallorqui, J. J., Berardino, P., Sansosti, E., 2004. A small-baseline approach for investigating deformations on full-resolution differential SAR interferograms. IEEE Transactions on Geoscience and Remote Sensing, Vol.42, No.7, pp.1377-1386.

Liu, G. X., Buckley, S. M., Ding X. L., Chen Q., Luo. X. J., 2009. Estimating spatiotemporal ground deformation with improved persistent-scatterer radar interferometry. IEEE Transactions on Geoscience and Remote Sensing, Vol.47, No.9, pp.3209-3219.

Masahiro C., Wu, X. Y., Takashi I., Wang, G. H., 2010. Landslides induced by the 2008 Wenchuan earthquake, Sichuan, China. Geomorphology, Vol.118, pp. 225-238.

Wang, Y. Y., Zhu, X. X., Bamler, R., 2012. Retrieval of phase history parameters from distributed scatterers in urban areas using very high resolution SAR data. ISPRS Journal of Photogrammetry and Remote Sensing, Vol.73, pp.89-99.

Zhang, L., Ding, X. L., Lu, Z., 2011. Modeling PSInSAR time series without phase unwrapping. IEEE Transactions on Geoscience and Remote Sensing, Vol.49, No.1, pp.547-556. 